\title{
The long and short of it
}

\section{It can take twice as long to get a PhD in biomedical sciences in the US as it does in other countries such as the UK and Australia. Are US PhDs worth more, or are there advantages to a speedier system?}

$\mathbf{N}$ othing illustrates the powerful lure of scientific discovery better than the choice of academic research as a career. In which other professions would you spend ten years in 'training' - working grueling hours for very little pay - with only a slim chance of securing a permanent job at the end of it all? Nowadays, such is the norm in biomedical research.

These days, even established principal investigators struggle to find funding for their projects, so the prospects for young scientists wanting to obtain that first grant look bleaker than ever. As funding gets tighter, the science arena becomes more competitive. In the past, a single high-profile publication may have sufficed to garner a permanent academic position but, in today's climate, one will no longer do. Unless graduate students are exceptionally lucky and prolific, a postdoc-or two-will be obligatory. If $\mathrm{PhD}$ work used to be viewed as the training for independent research, what is its value or purpose now?

There is a huge discrepancy in the length of time it takes to obtain a PhD in different countries. In the UK, Spain, Mexico and Australia, for example, the norm is three to four years. Graduate students in the US can be stuck in the lab for seven or eight years-or longer-before completing their PhDs. In part, the difference is due to what's expected from the degree. In countries in which the length of time for $\mathrm{PhD}$ completion is shorter, the PhD may be seen as more of a learning experience, and students can graduate without any publications provided that they've produced a reasonable thesis. Financial considerations also play a part: in the UK and Mexico, funding lasts for only three to four years and then students must leave.

Which is the better system probably depends on who you ask. Ask the students and they would probably prefer the short $\mathrm{PhD}$, as it allows them to try out research within a shorter time frame and get out early if they decide it's not for them. And if the purpose of a PhD is not simply training for a life in academia, but also training in the sort of intellectual discipline that can be used in activities aside from the bench, there are clear advantages to not lingering around. Even for those students who are keen to continue on in research, completing a $\mathrm{PhD}$ in three years allows them to pursue the next step in a different, perhaps more successful lab if they are not happy with the lab they chose as green, inexperienced novices.

Principal investigators might have a different viewpoint: why should they spend three years training a student, only for that student to leave the lab and pursue a postdoc elsewhere as soon as he or she becomes competent enough to do experiments without close supervision? It's only natural for researchers to want to maximize the return on their investment.

As scientists are a mobile, international bunch-first or second postdocs in another country are common-maybe $\mathrm{PhDs}$ should be standardized internationally, so that they carry the same weight everywhere.

However, what seem to matter more than the degree itselfat least for continuing on in academic research-are publications. Perhaps there is already an international standard: publications are evidence that the candidate has produced a solid piece of research. And, like it or not, the international measure for the quality of research is the quality of the publications that result from it.

It may be in the interest of some students to hasten the $\mathrm{PhD}$ and finish up within three years-largely of those who have decided academia is not for them. Perhaps such students should be encouraged to quit early and get out with a Master's degree. Leaving a $\mathrm{PhD}$ program with no publications puts an individual at a serious disadvantage in pursuing a research career, particularly if he or she wants to postdoc in the US. And there's no getting back three years.

On the other hand, seven or eight years for a $\mathrm{PhD}$ is clearly too long. Perhaps students simply need guidance in how to choose a lab in which they are likely to be productive. For example, students in the US get to 'rotate' through a few labs, spending a few months in each, before making a final choice.

At the end of the day, though, one pertinent question remains: how many publications constitute sufficient evidence of competitiveness and competence? The more publications are required to secure a permanent position, the longer the 'training' and the greater the risk in investing so much time for so few job opportunities at the end. Is the cycle warranted, and, if not, how do we break it? 